\title{
HUBUNGAN SENAM HAMIL DENGAN RASA NYAMAN TIDUR PADA IBU HAMIL TRIMESTER III
}

\author{
Riadinni Alita ${ }^{1}$ \\ 1Fakultas Ilmu Kesehatan Universitas Pembangunan Nasional “Veteran” Jakarta
}

\begin{abstract}
ABSTRAK
Usia kehamilan yang semakin bertambah akan menyebabkan ketidaknyamanan dan gangguan fisik dan keluhan istirahat/tidur. Ibu hamil yang maladaptif selama kehamilan berakibat komplikasi dan meningkatkan risiko Angka Kematian Ibu (AKI). Ibu hamil membutuhkan terapi selama trimester III untuk meningkatkan rasa nyaman selama hamil. Penelitian ini bertujuan untuk mengetahui hubungan senam hamil dengan rasa nyaman saat tidur pada ibu hamil trimester III. Desain penelitian menggunakan cross sectional. Sampel penelitian menggunakan uji T-Test dengan sampel 30 responden ibu hamil trimeser III yang mengkuti senam hamil di Puskesmas Kramat Jati Jakarta. Penelitian menggunakan kuesioner senam hamil dan tidur (alpha cronbach 0,94 ). Hasil penelitian menunjukkan $36,7 \%$ yang memiliki rasa nyaman tidur dan nilai pvalue < 0,05 . Hasil uji statistik didapatkan terdapat hubungan antara senam hamil dengan rasa nyaman tidur pada ibu hamil trimester III ( $\mathrm{p}$-value $=0,000$ ). Kesimpulan penelitian bahwa ada pengaruh yang signifikan senam hamil dengan rasa nyaman tidur pada ibu hamil trimester III. Saran pada ibu hamil trimester III melakukan senam hamil untuk meningkatkan kenyamanan dan tercapainya kecukupan kebutuhan waktu istirahat tidur. Senam hamil dilakukan melalui kelas ibu hamil untuk edukasi serta pemanfaatan lain pada senam hamil terhadap kehamilan.
\end{abstract}

Kata Kunci: kehamilan trimester III, senam hamil, rasa nyaman saat tidur

\begin{abstract}
Increasing gestational age will cause discomfort and physical disturbance and sleep problems. Pregnant women who are maladaptive during pregnancy, experience an increase and increase the Maternal Mortality Rate (MMR). Pregnant women need therapy during the third trimester to increase comfort during pregnancy. This study aims to study the relationship of pregnancy exercise with a sense of comfort while sleeping in third trimester pregnant women. The study design uses cross sectional method. The research sample uses a T-Test with a sample of 30 respondents in third trimester pregnant women who follow pregnancy exercises at the Kramat Jati Health Center in Jakarta. The study used questionnaires for pregnancy and sleep exercises (Cronbach's alpha 0.94). The results showed that $36.7 \%$ had a comfortable sleep and a $p$ value $<0.05$. Statistical test results obtained about the relationship between pregnancy exercise with a sense of sleep comfort in third trimester pregnant women ( $p$-value $=0,000$ ). The conclusion of the study was that there was a significant effect on pregnancy exercise with a sense of sleep comfort in third trimester pregnant women. Suggestions for third trimester pregnant women do pregnancy exercises to improve comfort and adequacy of sleep rest needs. Pregnant gymnastics is carried out through classes of pregnant women for education and provided other exercises on pregnancy for pregnancy.
\end{abstract}

Keywords: pregnancy comfort in sleep, pregnancy exercise, third trimester pregnancy.

Alamat Korespondensi: FIKES UPN Veteran Jakarta, Jalan Limo Raya Kelurahan Limo Kecamatan Limo Kota Depok Kode Pos 16515, Telp. 021-7532884, Fax 021-7546772

Email: riadinnialita@upnvj.ac.id 


\section{PENDAHULUAN}

Kehamilan merupakan tahap transisi proses kehidupan perempuan yang matur secara reproduksi dan calon seorang ibu. Kehamilan ialah pengalaman bahagia ibu, tetapi pada kasuskasus tertentu kehamilan mengalami gangguan, komplikasi bahkan meningkatkan risiko Angka Kematian Ibu (AKI) (Afiyanti, 2004; Ummah, 2015). Selama kehamilan terjadi berbagai perubahan yang dialami secara fisik dan psikologis sehingga berakibat menimbulkan berbagai ketidaknyamanan. Kehamilan adalah hal yang fisiologis, namun memengaruhi metabolik janin dan ibu (Jen et al.,2010; Natan, et al.,2010).

Ibu hamil mengalami berbagai perubahan sebagai bentuk proses adaptasi. Perubahan yang dialami ibu hamil diantaranya kadar hormon progesteron dan estrogen, uterus yang membesar, sistem sirkulasi, peningkatan frekuensi berkemih, nyeri dan payudara membesar, kelelahan, dan kepanasan. Volume darah meningkat dan respon dilatasi otot mengakibatkan adaptasi lainnya berupa konstipasi, varises atau hemoroid, penurunan motilitas usus (Marques, Demain \& Sa-Couto, 2015). Perubahan psikologis yang dialami selama kehamilan berupa stres, peningkatan kecemasan, penurunan harga diri, citra tubuh, konsep diri, dan motivasi. Ibu hamil yang tidak mampu beradaptasi terhadap kehamilannya akan memicu gangguan lebih berat atau komplikasi kehamilan (Nayak, Poddar, \& Jahan, 2015).

Pada trimester III dan semakin mendekati waktu persalinan, ibu hamil kesulitan posisi dan waktu tidur. Menurut National Sleep Foundation (2007) bahwa presentasi ibu hamil yang mengalami gangguan tidur mencapai 79\% (Rezaei,2015). Adaptasi sistem pernafasan pada ibu hamil akan memengaruhi pasokan oksigen di otak sehingga mengganggu kualitas tidur (Emilia, 2010). Kuantitas tidur ibu hamil yang kurang dari lima jam pada malam hari berisiko meningkatkan risiko hipertensi (William et al.,2010). Ibu hamil dengan kualitas tidur yang buruk meningkatkan respon inflamasi melalui sekresi sitokin. Sitokin yang diproduksi berlebih akan memengaruhi arteri ke plasenta sehingga menyebabkan gangguan sirkuasi dan persalinan prematur (Okun,2011). Studi pendahuluan yang dilakukan di Puskesmas Kramat Jati bulan Maret 2011 bahwa delapan dari sepuluh ibu hamil trimester III mengalami gangguan tidur yang disebabkan karena gerakan janin, sering BAK, nyeri pinggang, kepanasan, dan nafas pendek. Oleh karena itu, kualitas tidur yang baik pada ibu hamil berdampak positif bagi perencanaan persalinan yang baik dan lancar sehingga dibutuhkan penanganan yang tepat agar ibu hamil mencapai kenyamanan selama kehamilan.

Menurut Hegard et al.(2010) menjelaskan terdapat beberapa teknik mengatasi kesulitan mencapai rasa nyaman tidur atau kualitas tidur yang baik antaranya edukasi tidue, hipnoterapi, mengkonsumsi obat-obat yang aman selama kehamilan, olahraga, dan latihan relaksasi. Latihan terbukti membantu ibu hamil menurunkan keluhan nyeri punggung, kecemasan dan istirahat tidur (Connolly et al.,2014). Salah satu latihan yang dilakukan selama masa kehamilan senam hamil.

Senam hamil adalah salah satu pelayanan prenatal yang mambantu ibu beradaptasi dengan perubahan fisiologis melalui gerakan dan relaksasi otot sehingga ibu merasakan lebih nyaman (Roosytasari, 2009). Selain itu, relaksasi yang didapatkan oleh ibu hamil akan mengurangi ketegangan dan menurunkan kecemasan sehingga ibu lebih siap menghadapi persalinan. Senam hamil yang efektif bila dilakukan secara teratur. Ibu hamil yang mengikuti senam hamil teratur dan intensif akan meningkatkan status kesehatan ibu dan janin dalam kandungan (Wahyuni \& Ni'mah, 2013). Latar belakang permsalahan dan akibat yang ditimbulkan pada gangguan tidur yang dialami oleh ibu hamil trimester III sehingga tujuan penelitian yaitu mengetahui hubungan senam hamil dengan rasa nyaman tidur ibu hamil trimester III.

\section{METODE PENELITIAN}

Desain penelitian menggunakan metode cross sectional. Penelitian ini untuk menganalisis hubungan antara senam hamil dengan rasa nyaman tidur pada ibu hamil trimester III di wilayah Puskesmas Kramat Jati, Jakarta. Penelitian dilakukan dari bulan April sampai Mei 2011. Sampel 
merupakan ibu hamil trimester III (27 - 40 minggu) yang mengikuti senam hamil di Puskesmas Kramat Jati. Kriteria inklusi adalah pasien KIA yang setidaknya dua kali pemeriksaan prenatal dan mengikuto kelas senam hamil setidaknya empat kali dalam sebulan, tidak memiliki penyakit penyerta kehamilan, tidak mengikuti latihan atau terapi lainnya, tidak memiliki riwayat kontraksi dini, abortus dan perdarahan, mampu berbahasa Indonesia dan membaca, ibu hamil trimester III, kondisi emosional yang baik dan kooperatif. Responden akan telah mengikuti berupa latihan senam hamil yang dilakukan satu kali dalam seminggu selama satu bulam yang dipimpin oleh peneliti dan bidan KIA.

Instrumen yang digunakan dalam penelitian adalah lembar observasi kegiatan senam hamil yang diisi setiap responden datang dan mengkuti kelas prenatal dan peneliti menggunakan kuesioner. Uji validitas didapatkan 20 pertanyaan senam hamil dan 10 rasa nyaman tidur valid dengan reabilitas nilai alpha cronbach 0,94 dan uji validitas lebih dari nilai $r$ tabel $(>0,361)$. Analisa statistik penelitian menggunakan independent t-tes dan paired $t$-test. Etika yang digunakan yaitu autonomy, anonimity, freedom from harm, dan the right to fair treatment.

\section{HASIL DAN PEMBAHASAN Karakteristik Responden}

Responden dalam penelitian merupakan ibu hamil trimester III yang melakukan pelayanan antenatal dan mengikuti kelas senam hamil di Puskesmas Kramat Jati, Jakarta. Total sampel digunakan dalam penelitian, 30 responden yang mengkuti kelas prenatal senam hamil dan wajib melaksanakan senam hamil setiap minggunya. Analisis univariat dari variabel- variabel dalam penelitian ini meliputi umur ibu hamil, jenis pendidikan, jenis pekerjaan, paritas, dan usia kehamilan ibu.

Tabel 1. Distribusi Frekuensi Data Umur Ibu dan Usia Kehamilan Hamil Trimester III(n=30)

\begin{tabular}{lllll}
\hline Karakteristik & Mean & SD & Min & Max \\
\hline Umur Ibu Hamil & 28,67 & 4,94 & 17 & 38 \\
\hline Usia Kehamilan & 34,37 & 2,11 & 30 & 37 \\
\hline
\end{tabular}

Berdasarkan tabel 1 menunjukkan bahwa data umur ibu hamil trimester III yang mengikuti senam hamil memiliki rata- rata 28,67. Umur termuda ibu hamil adalah 17 tahun dan umur paling tua ialah 38 tahun. Sejalan dengan penelitian Sukorini (2017) bahwa umur optimal untuk hamil antara 20- 35 tahun. Umur ibu yang remaja semakin tua akan meningkatkan risiko komplikasi dalam kehamilan dan persalinan. WHO merekomendasikan umur yang optimal dan aman menjalani kehamilan antara 20-30 tahun. Pada kondisi tersebut secara maturitas dan kesiapan fisik perempuan dengan prima. Uterus matur untuk menerima janin dan mental dipersiapkan dalam merawat kehamilan dengan baik. Ditambahkan oleh Tamher \& Norrkasisiani (2009) bahwa bertambahnya umur ibu maka semakin baik mengontrol diri, menggunakan koping terhadap stresor yang diterima. Sedangkan, kehamilan dan persalinan yang dihadapi dibawah umur 20 tahun akan berisiko mengalami post partum blues hingga depresi post partum (Pitriani \& Andriyani, 2014).

Semakin bertambah usia kehamilan pada trimester III dan semakin mendekati waktu melahirkan akan memengaruhi kenyamanan ibu dalam mencapai kualitas tidur yang baik. Ketidaknyamanan yang dialami ibu hamil dirasakan semakin berat seiring dengan usia kehamilan. 
Perubahan tidur dikarenakan frekuensi berkemih, nyeri punggung atau pinggul sehingga sulit menentukan posisi yang nyaman (Suzuki,2009). Trimester III adalah periode ibu hamil membutuhkan perhatian dan kebutuhan khusus karena akan dihadapkan pada proses persiapan persalinan. Ibu hamil dengan persiapan yang kurang akan mengahadapi peningkatan kecemasan dan ketakutan. Hal ini dapat mengakibatkan risiko hambatan saat persalinan nantinya (Mediarti et al., 2014).

Tabel 2. Distribusi Frekuensi Pendidikan, Pekerjaan, Paritas, Senam Hamil dan Rasa Nyaman Tidur $(n=30)$

\begin{tabular}{lll}
\hline Karakteristik & Frekuensi (n) & Presentase (\%) \\
\hline Pendidikan & & \\
Rendah (SD,SMP) & 12 & $40 \%$ \\
Tinggi (SMA, PT) & 18 & $60 \%$ \\
\hline Pekerjaan & & \\
Tidak bekerja & 13 & $43,3 \%$ \\
Bekerja & 17 & $56,7 \%$ \\
\hline Paritas & & \\
Primigravida & 13 & $43,3 \%$ \\
Multigravida & 17 & $56,7 \%$ \\
\hline Senam Hamil & & \\
Rendah & 0 & $0 \%$ \\
Sedang & 9 & $30 \%$ \\
Tinggi & 21 & $70 \%$ \\
\hline Rasa Nyaman Tidur & & \\
Rendah & 1 & $3,3 \%$ \\
Sedang & 11 & $36,7 \%$ \\
Tinggi & 18 & $60 \%$ \\
\hline
\end{tabular}

Berdasarkan tabel 2 data diperoleh bahwa mayoritas ibu hamil memiliki pendidikan tinggi (SMA,PT) 18 responden (60\%), bekerja 17 responden (56,7\%), multipara 17 responden (56,7\%). Seseorang dengan tingkat pendidikan tinggi akan memiliki peluang lebih besar mencari informasi dan pengobatan pada pelayanan kesehatan. Sebaliknya, semakin rendah pendidikan maka semakin memicu stres atau kecemasan yang disebabkan kurangnya informasi yang diperoleh.

Ibu hamil trimester III mengalami keluhan yang dirasa semakin berat sehingga akan mengganggu istirahat dan tidur. Ibu hamil membutuhkan sekitar delapan jam untuk tidur (Siswosuhardjo, 2010). Sejalan dengan penelitian Mendell et al.(2015) bahwa 76\% ibu hamil trimester III mengalami tidur yang buruk. Penyebab hal tersebut diantaranya sering terbangun di malam hari, gejala insomnia. Gangguan lain yang dirasa yaitu sering buang air kecil, gangguan nafas, kesulitan menemukan posisi yang nyaman.

Pengalaman terhadap kehamilan dan melahirkan sebelumnya akan memengaruhi kondisi fisik dan atau psikologis ibu hamil. Ibu primigravida belum memiliki pengalaman sehingga merasa lebih cemas dalam mempersiapkan atau menghadapi persalinan. Sebaliknya, Ibu multipara dapat lebih 
mengatasi kecemasan berdasarkan pengalaman melahirkan yang dialami sebelumnya (Prasadja, 2009). Sejalan dengan penelitian yang dilakukan Sukorini (2017) banyaknya ibu multigravida yang memiliki kualitas tidur buruk disebabkan faktor-faktor lain yang memengaruhinya. Faktor tersebut berupa pengalaman yang tidak menyenangkan pada proses melahirkan sebelumnya, kurangnya dukungan pendamping ibu hamil, kelelahan, kesiapan kehamilan yang meningkatkan kecemasan selama kehamilan (Sreesupriya, 2014).

Tabel 3. Hubungan Senam Hamil dengan Rasa Nyaman Tidur Ibu Hamil (n=30)

\begin{tabular}{lllllll}
\hline Variabel & Mean & SD & SE & 95\% Ci & T & p-value \\
\hline Senam Hamil & 16,53 & 3,579 & 0,653 & 8,096 & & \\
\cline { 1 - 4 } Rasa Nyaman Tidur & 7,53 & 2,330 & 0,425 & 9,904 & & 0,000 \\
\hline
\end{tabular}

Berdasarkan tabel tiga menunjukkan bahwa terdapat hubungan yang bermakna antara senam hamil dengan rasa nyaman tidur pada ibu hamil trimester III di wilayah kerja Puskesmas Kramat Jati, Jakarta tahun 2011 (p-value $=0,000 ; 95 \%$ Ci). Sejalan dengan penelitian yang dilakukan Wahyuni \& Ni'mah (2013) bahwa mengalami sulit tidur. Ketidaknyamanan yang muncul disebabkan oleh perubahan hormonal ketika hamil yang mengganggu secara fisik dan emosional. Sekresi hormon yang tidak seimbang berupa produksi kortisol, katekolamin, ACTH, epinefrin, norepinefrin, prostaglandin dan serotonin (Alder et al., 2007).

Penurunan kualitas dan durasi tidur akibat meningkatnya ketidaknyamanan fisik dan kecemasan. Kecemasan ialah refleksi kesadaran bahwa persalinan semakin dekat sehingga menimbulkan kekhawatiran dan waspada. Perasaan tersebut berupa kesehatan keadaan kesehatan diri dan bayi, khawatir bayi lahir tidak normal, dan proses melahirkan apakah akan berjalan baik.Respon yang tergambar akibat ketidaknyamanan tersebut akan beragam tergantung koping setiap ibu hamil. Ibu hamil membutuhkan alternatif intervensi yang dilakukan untuk meningkatkan kenyamanan dan mencapai kualitas tidur yang baik selama trimester III. Salah satu intervensi tersebut adalah senam hamil. Ketidaknyamanan fisik dan kecemasan ialah stresor kemudian merangsang syaraf simpatis dan modula kelenjar adrenal sehingga mensekresi hormon epinefrin. Hormon epinefrin mengakibatkan ibu hamil tegang, sulit fokus atau konsentrasi sehingga ibu hamil semakin gelisah. Ketidaknyamanan lebih lanjut akan membuat ibu kesulitan untuk nyaman tidur, kualitas tidur yang buruk, dan penurunan durasi tidur (Wulandari, 2006).

Menurut American College of Obstetricans and Gynecologist (ACOG) menjelaskan bahwa senam hamil merupakan serangkaian gerakan tubuh untuk melatih kebugaran dan penguatan otot yang bertujuan mensekresi hormon endorfin secara alami. Hormon endorfin memberikan sensasi relaks dan mengurangi keluhan nyeri selama kelamilan dan persalinan (Yuniastari et al., 2015). Senam hamil melibatkan sistem syaraf parasimpatis yang berfungsi penekan produksi hormon epinefrin (adrenalin) dan mensekresi hormon norepinefrin sehingga ibu hamil lebih rileks (Corry,2004;Wulandari,2006). Senam hamil terdiri dari latihan pernafasan dan relaksasi otot sehingga emosi ibu hamil lebih stabil. Relaksasi yang dilakukan dalam senam hamil akan menurunkan nyeri, kecemasan, dan rasa takut yang timbul masa kehamilan (Mafikasari \& Kartikasari, 2015). Senam hamil juga menghasilkan sekresi hormon enkefalin. Hormon enkefalin bekerja dengan hormon endorfin sebagai inhibitor transmisi nyeri (Rahmawati et al.,2015). 


\section{SIMPULAN}

Hasil penelitian menunjukkan ada hubungan pelaksanaan senam hamil terhadap peningkatan rasa nyaman tidur pada ibu hamil trimester III. Salah satu alternatif latihan fisik selama kehamilan adalah senam hamil. Senam hamil yang dilakukan secara teratur dan berkala akan menurunkan ketidaknyamanan dan membantu ibu mencapai kualitas tidur yang baik.

\section{SARAN}

Implikasi terkait senam hamil adalah penyediaan kelas prenatal berupa kelas senam hamil yang dikembangkan lebih lanjut untuk memfasilitasi ibu hamil dapat konseling dan focus group discussion sehingga ibu hamil satu dengan lainnya berbagi pengalaman dan menemukan hal positif dan terapi yang dapat diterapkan pada ibu hamil lainnya. Pembuat kebijakan di layanan prenatal memberikan fasilitator tenaga kesehatan yang terlatih untuk memfasilitasi senam hamil dengan tepat dan benar. Penyediaan fasilitas kelas senam hamil yang nyaman dan luas sehingga ibu hamil nyaman selama mengikuti kelas hamil. Faktor kenyamanan berupa luas, pencahayaan, kelembaban, suhu udara memengaruhi selama pelaksanaan senam hamil. Hal tersebut menjadi penting dipertimbangkan oleh pelatih atai fasilitator.

\section{DAFTAR PUSTAKA}

Afiyanti, Y. (2004). Studi Fenomenologi tentang Pengalaman Wanita Di Daerah Pedesaan dalamMenjalani Masa Kehamilan Pertama. Jurnal Keperawatan Indonesia, 8(2), 62-69. http://doi.org/http://dx.doi.org/10.7454/jki.v8i2.149

Alder J., Fink, N., Bitzer, J., Hosli, I., \& Holzqreve, W. (2007). Depression and anxiety during pregnancy: a risk factor for obstetric, fetal and neonatal outcome? A critical review of the literature. J Matern Fetal Neonatal Med; 20(3):189-209

Connolly, C. P., Feltz, D. L., \& Pivarnik, J. M. (2014). Overcoming Barriers to Physical Activity During Pregnancy and the Postpartum Period: The Potential Impact of Social Support. Kinesiology Review, 3, 135-148. http:// doi.org/http://dx.doi.org/10.1123/kr.2013-0009

Corry M. (2004). Guidelines For Exercise in Pregnancy. University of Western Australia

Emilia, O. (2010). Tetap Bugar dan Energik Selama Hamil. Jakarta: Agromedia

Hegaard, H. K., Kjaergaard, H., Damm, P. P., Petersson, K., \& Dykes, A. (2010). Experiences of physical activity during pregnancy in Danish nulliparous women with a physically active life before pregnancy . A qualitative study. BMC Pregnancy and Childbirth, 10(33), 1-10. http://doi.org/10.1186/1471-2393-10-33

Mafikasari A, Kartikasari RI. Posisi Tidur dengan Kejadian Back Pain (Nyeri Punggung) Pada Ibu Hamil Trimester III. Surya. 2015;7:26-34.

Marques, A., Demain, S. H., \& Sa-Couto, P. (2015). Women's experiences of low back pain during pregnancy. Journal of Back and Musculoskeletal Rehabilitation, 28, 351-357. http://doi.org/10.3233/BMR-140527

Mediarti D, Sulaiman S, Rosnani R, Jawiah J. (2014). Pengaruh Yoga Antenatal Terhadap Pengurangan Keluhan Ibu Hamil Trimester III. J Kedokt Kesehat Publ Ilm Fak Kedokt Univ Sriwij [Internet]. 2014;1(1):47-53. Available from: http:/ / ejournal.unsri.ac.id/index.php/jkk/article/view/2567/0

Mindell, J., Cook, R., Nikolovski, J. 2015. Sleep patterns and sleep disturbances across pregnancy. J. Sleep. Vol. $\quad 16 . \quad$ No. 4 Hal.483488. diakses https://www.researchgate.net/publication/272095499_Sleep_patterns_and_sleep_disturbance s_across_pregnanc. [ Diakses tanggal 12 Januari 2020] 
Nayak, S. K., Poddar, R., \& Jahan, M. (2015). Psychological Problems during Advance Stage of Pregnancy. The International Journal of Indian Psychology, 2(2), 103-113.

Natan, G., Levy, M., Giovenardi, M., \& Tufik, S. (2010). Sleep impairment during pregnancy : Possible implications on mother - infant relationship. Medical Hypotheses, 75(6), 578-582. http://doi.org/10.1016/j.mehy.2010.07.036

Okun, M. (2011). Poor Sleep Quality is Associated with Preterm Birth.J. Sleep.Vol 34. Nomor 11.. Halaman 1493-1498 Tersedia di http://www.journalsleep.org/ViewAbstract.aspx?pid=28329[Diakses tanggal 10 Januari 2020]

Pustaka. Jen, J., Pien, G. W., Duntley, S. P., \& Macones, G. A. (2010). Sleep deprivation during pregnancy and maternal and fetal outcomes : Is there a relationship ? Sleep Medicine Reviews, 14(2), 107-114. http://doi.org/10.1016/j.smrv.2009.05.001

Pitriani. R., Andriyani, R. (2014). Panduan Lengkap Asuhan Kebidanan Ibu Nifas Normal (Askeb III). Yogyakarta: Deepublish.

Prasadja, A. 2009. Ayo Bangu dengan Bugar karena Tidur yang Benar. Bandung: Hikmah.

Rahmawati P, Musviro, Fitrio D. (2015). Efektifitas Progressive Muscle Relaxation (PMR) Terhadap Penurunan Tekanan Darah pada Penderita Hipertensi. Indones J Heal Sci [Internet]. 2015;188-93. Available from: http://repository.unej.ac.id/bitstream/handle/123456789/89700/F. Kep_Jurnal_Primasari MR_EFEKTIFITAS PROGRESSIVE MUSCLE RELAXATION.pdf?sequence=1

Rezaei E.,Moghadam Z.B., Hagani H. (2015). The Effect of Sleep Health Behavioral Education on the Depression of Pregnant Women With Sleep Disorders: A Randomized Control Trial. Iranian Red Crescent Medical Journal. Jan; 17(1). doi: 10.5812/ircmj.11420

Roosytasari, Locana.(2009).Hubungan Antara Senam Hamil dengan Proses Persalinan Normal di Rumah Bersalin As Syifa'ul Ummah Grobogan.Skripsi.Tidak diterbitkan.Fakultas Kedokteran Universitas Muhammadiyah. Surakarta, http://mitrariset.com/skripsi-thesis/file-218/

Siswosuhardjo, S., Chakrawati, F. (2010). Panduan Super Lengkap Hamil Sehat.Jakarta: Penebar Plus + .

Sreesupriya. (2014). A Study on Sleep Disturbances Among Antenatal Women Attending A Tertiary Care Hospital, in Chennai, Tamilnadu. Indian Journal of Applied Research. Vol 4. Nomor $10 . \quad$ Halaman 426-428. Tersedia di https://www.worldwidejournals.com/indianjournal-of-applied-research-(IJAR)/ fi le.php?val=October_2014_1413535698_132.pdf[ Diakses tanggal 14 Januari 2020]

Sukorini, Mariyam Ulfa.(2017).Hubungan Gangguan Ketidaknyamanan Fisik dan Penyakit dengan Kualitas Tidur Ibu Hamil Trimester III.The Indonesian Journal of Public Health,Vol.12 No.1; 1-12. doi: 10.20473/ijph.v12i1.2017.1-12

Suzuki. (2009). Sleeping Patterns During Pregnancy in Japanese Women. Journal of Psychosomatic Obstertrics \& Ginecology. Vol. 15. Nomor 1. Halaman 19-26. Tersedia di <https://www.ncbi.nlm.nih.gov/pubmed/8038885> [Diakses tanggal 13 Desember 2016

Tamher, S., Noorkasiani. (2009). Pendidikan Usia Lanjut dengan Pendekatan Asuhan Keperawatan. Jakarta: Salemba Medika.

Ummah, F. (2015). Kontribusi Faktor Risiko I terhadap Komplikasi Kehamilan Di Rumah Sakit Muhammadiyah Surabaya. SURYA, 7(1). Retrieved from http://stikesmuhla.ac.id/wpcontent/uploads/jurnalsurya/Jurnal April Vol.07 No.01 April 2015 Pdf/01-08 jurnal april 2015 Faiz.pdf

Wahyuni \& Ni'mah, Layinatun.(2012).Manfaa Senam Hamil untuk Meningkatkan Durasi Tidur Ibu 
Hamil.Jurnal Kesehatan Masyarakat No.8 Vol.2.145-152.

Williams, M., Miller, R., Qiu, C., Cripe, S., Gelaye, B., Enquobahrie, D. (2010). Associations of Early Pregnancy Sleep Duration with Trimester-Specifi c Blood Pressures and Hypertensive Disorders in Pregnancy.J.Sleep. Vol. 33. Nomor 10. Halaman 1363-1371. Tersedia di: https://www.ncbi.nlm.nih.gov/pmc/articles/PMC2941423/[ Diakses tanggal 15 Januari 2020]

Wulandari P. Y. (2006). Efektivitas Senam Hamil Sebagai Pelayanan Prenatal Dalam Menurunkan Kecemasan Menghadapi Persalinan Pertama. INSAV, 8(2): 144

Yuniastari, Annisa Dwi P, Siti Fatimah P RDi. (2014).Analisis FaktorFaktor Yang Berhubungan Dengan Pelaksanaan Senam Hamil Di Wilayah Puskesmas Purwokerto Barat Tahun 2013. Kesehat Masy. 2014;2:283-91. 